\title{
Strategi Membelajarkan Penguasaan Fakta Dasar Matematika (Mathematics Basic Fact Fluency) Siswa Sekolah Dasar
}

\section{Dana Arif Lukmana}

Fakultas Tarbiyahdan Ilmu Keguruan, IAIN Ternate E-mail: danalukmana@iain-ternate.ac.id

\begin{abstract}
ABSTRAK
Penguasaan fakta dasar matematika merupakan komponen penting perkembangan keterampilan matematika siswa yang sangat diperlukan. Penulis merekomendasikan agar dalam membelajarkan fakta dasar diawali dari fase menghitung, bernalar hingga penguasaan.Implemantasinya meliputi menyajikan masalah riil dan membiarkan siswa mengembangkan strategi alaminya secara mandiri.Terkait fakta penjumlahan, strategi penalaran dapat dilakukan dengan aktifitas tambah satu tambah dua, penjumlahan dengan 0, menggunakan 5 atau 10 sebagai acuan, kelipatan dua, hingga dekat kelipatan dua. Untuk fakta perkalian strategi penalaran dapat dilakukan dengan perkalian 0,2,5,9 dan 10, dilanjutkan memanfaatkan fakta-fakta yang sudah diketahui untuk menemukan fakta baru, dan penggunaan game sebagai latihan. Sebagai catatan, beberapa hal perlu dihindari dalam membelajarkan fakta dasar matematika seperti mengabaikan strategi yang dikembangkan sendiri oleh siswa, menghafal, tes berdurasi, dan menjadikan penguasaan fakta menjadi syarat utama belajar pengalaman matematika lebih lanjut.
\end{abstract}

Kata kunci: Penguasaan, Strategi, Fakta Dasar Matematika

\section{Pendahuluan}

Ide awal dari penelitian ini adalah berasal dari buah pikiran tentang dua contoh soal sederhana berikut ini: 1) Faktorkan persamaan kuadrat: $x^{2}+13 x+42=0$

2) Tentukan hasil penjumlahan dua pecahan berikut. $2 \frac{1}{6}+\frac{3}{7}$. Untuk menyelesaikan soal pertama, pada umumnya siswa mengawalinya dengan menjawab pertanyaan sebagai berikut: "apakah dua bilangan (sebut $a$ dan )yang mana jika keduanya dijumlahkan hasilnya $13(a+b=13)$ dan jika dikalikan hasilnya $42(a \times b=42)$ ". Agar memperoleh jawaban yang benar, siswa harus mengetahui kombinasi-kombinasi dua bilangan yang yang jika dijumlahkan hasilnya 13, dan jika dikalikan hasilnya 42 . Pada soal yang kedua, siswa menyelesaikannya dengan beberapa langkah: 1) mengubah pecahan campuran $2 \frac{1}{6}$ menjadi pecahan biasayaitu $\frac{13}{6}$, 2) menentukan KPK 
dua bilangan 6 dan 7 yaitu 42, 3) membagi KPK (6 dan 7) dengan 6 kemudian mengalikan hasilnya dengan $13(7 \times 13)$, 3) membagi KPK $(6$ dan 7) dengan 7 kemudian mengalikannya dengan $3(6 \times 3), 4)$ menjumlahkan hasil langkah 2 dan 3 , dan 5) menyederhanakan pecahan/mengubah hasil akhir menjadi pecahan campuran. Jika diperhatikan penyelesaian dua soal di atas, untuk memperoleh jawaban benar keduanya mensyaratkan siswa memiliki penguasaan serta kelancaran terkait fakta dasar matematika yang meliputi fakta-fakta penjumlahan, pengurangan, perkalian dan pembagian.Menurut Frawly (2012) kelancaran (fluency) matematika dapat dilihat jika siswa dapat menghitung secara mental fakta-fakta penjumlahan, pengurangan, perkalian dan pembagian dengan benar dan dalam waktu yang relatif cepat.Dalam hal ini, kelancaran matematika juga dapat diartikan sebagai otomatisasi.Artinya, siswa secara cepat dan tepat menyelesaikan masalah yang melibatkan fakta-fakta penjumlahan, pengurangan, perkalian dan pembagian .Keterampilan matematika seperti operasi pada bilangan pecahan, pemfaktoran bentuk aljabar tentu akan menjadi lebih mudah dan sederhana dengan otomatisasi fakta penjumlahan dan perkalian (woodward, 2006). Bahkan Greaney (2015) menyatakan bahwa otomatisasi memungkinkan ruang kognitif siswa untuk dapat memecahkan masalah matematika yang lebih kompleks, karenanya kemampuan untuk memecahkan masalah terkait fakta dasar matematika terlalu penting untuk diabaikan.

Dalam praktiknya, keterampilan terkait fakta dasar matematika ini sering kali diabaikan.Banyak guru matematika di tingkat dasar (SD) lebih berfokus pada pemecahan masalah matematika dengan tanpa cukup peduli pada penguasaan fakta dasar.Akibatnya, banyak guru mendapati siswa cenderung mengembangkan keterampilan pemecahan masalah tanpa disertai upaya pengembangan kelancaran fakta dasar (Krudwig, 2003).Hal ini bisa berimbas pada lemahnya kelancaran fakta matematika siswa dan akan mengarah pada munculnya hambatan pada saat siswa memecahkan masalah matematika.

Beberapa studi menunjukkan pentingnya siswa mencapai kelancaran fakta matematika.Studi yang dilakukan oleh Codding dkk (2016) di Universitas Minnesota menunjukkan bahwa profil keterampilan penguasaan fakta dasar matematika dapat digunakan untuk memprediksi hasil belajar matematika siswa sekolah dasar dan menengah. Artinya, kelancaran fakta matematika memiliki relevansi dengan hasil belajar matematika.Nelson dkk (2016) dalam studinya menyimpulkan ketika siswa sukses dalam tes fakta dasar matematika single digit memiliki kecenderungan memperoleh hasil yang baik pada ujian nasional matematika. 


\section{PEMBAHASAN}

\section{Bagaimana Tahapan Perkembangan Penguasaan Fakta Dasar Matematika?}

Untuk mencapai penguasaan fakta dasar matematika, ada beberapa fase yang harus dilalui siswa. Baroodi (2006) mendeskripsikan tiga fase yang perlu dilalui:

1. Fase 1: Strategi Menghitung dengan menggunakan objek hitung misalnya menggunakan jari, koin, permen, buah atau menghitung secara verbal. Contoh, misal siswa menghitung $8+5$, maka bisa dilakukan dengan memulainya dari 8, kemudian menghitungnya secara verbal 9,10,11,12,13.

2. Fase 2: Strategi Penalaran yaitu menggunakan informasi yang diketahui kemudian secara logis menentukan kombinasi bilangan yang tidak diketahui. Contoh, siswa menghitung $8+7$, siswa tahu bahwa $8+8=16$, sehingga $8+7$ cukup dengan mengurangkan 1 dari 16 sehingga diperoleh 15.

3. Fase 3: Menguasai, siswa secara efisien (cepat dan akurat) menghasilkan jawaban. Misalnya, diminta minta menghitung 9+13, secara cepat dan akurat langsung menjawab 22.

Sedangkan dengan lebih detail Henry dkk (2008) menjabarkan tahapan perkembangan penguasaan fakta dasar sebagaimana tabel berikut.

\section{Menghitung (counting)}

\section{Penjumlahan}

Pemodelan langsung (objek hitung dan jari)

- Menghitung semua (counting all)

- Menghitung dari pertama

- Menghitung dari yang terbesar

Menghitung secara abstrak

- Menghitung semua (counting all)

- Menghitung dari pertama

- Menghitung dari yang terbesar

\section{Pengurangan}

Menghitung objek

- Memisahkan dari

- Memisahkan ke

- Menambahkan

Menghitung menggunakan jari

- Menghitung mundur (counting down)

- Menghitung maju(counting up)

Menghitung secara abstrak

- Menghitung mundur (counting down) 


\begin{tabular}{|c|c|c|}
\hline & & $\begin{array}{l}\text { - Menghitung } \\
\text { maju(counting } \\
\text { up) }\end{array}$ \\
\hline $\begin{array}{l}\text { Bernalar } \\
\text { (reasoning) }\end{array}$ & $\begin{array}{l}\text { Sifat-sifat } \\
\text { - } a+0=a \\
\text { - } a+1 \text { adalah bilangan cacah } \\
\quad \text { selanjutnya } \\
\text { - Sifat komutatif } \\
\text { Penurunan dari fakta yang diketahui } \\
\text { Misal } 6+5=5+1+5=5+5+1 \text {, atau } \\
7+6=7+7-1 \\
\text { Mendistribusi } \\
\text { diturunkan } \\
\text { Misal fakta yang } \\
8+(2+5)=(8+2)+5=10+5=15\end{array}$ & $\begin{array}{l}\text { Sifat-sifat } \\
\bullet \quad a-0=a \\
\bullet \quad a-1 \quad \text { adalah } \\
\quad \text { bilangan cacah } \\
\text { sebelumnya } \\
\text { Invers/komplemen } \\
\text { dari fakta } \\
\text { penjumlahan ayang } \\
\text { diketahui } \\
\text { Misal } \\
\text { diketahui karena } \\
\text { 7+5=12 } \\
\text { Mendistribusi fakta } \\
\text { yang diketahui } \\
\text { 12-7=(5+7)- } \\
\text { 7=5+(7-7)=5+0=5 }\end{array}$ \\
\hline $\begin{array}{lr}\text { Mengingat } & \text { dari } \\
\text { memori } & \text { Jangka } \\
\text { Panjang (Retrieval) }\end{array}$ & $\begin{array}{l}\text { Mengingat dari memori Jangka } \\
\text { Panjang }\end{array}$ & $\begin{array}{l}\text { Mengingat dari } \\
\text { memori } \\
\text { Panjang }\end{array}$ \\
\hline
\end{tabular}

\section{Bagaimana Cara Membelajarkan Fakta Dasar Matematika?}

Dalam kehidupan sehari-hari baik di sekolah maupun dirumah, belajar matematika tingkat dasar khususnya fakta matematika lebih identik dengan mengingat daripada berpikir. Bahkan seringkali pembelajarannya tidak mengakomodasi perbedaan diantara siswa secara individual misalnya praktik pembelajaran yang terlalu kaku (rigid), menggunakn dril yang terlalu sering, tes berwaktu serta keinginan yang terlalu prematur dari guru agar siswanya segera mencapai performa yang baik. Hal ini tentu sangat merugikan siswa dan akan menimbulkan pada kecemasan (anxiety) dan merusak pemahaman siswa. Boaler (2015) menegaskan bahwa mengingat fakta matematika melalui pengulangan, serta tes berwaktu sangat tidak perlu dan berbahaya.

Hal pertama yang bisa dilakukan adalah guru membantu siswa memperhalus dan mengembangkan strategi alaminya dalam menyelesaikan masalah matematika yang sederhana. Secara perlahan siswa akan mulai mengingat fakta-fakta matematika 
sederhana seiring dengan meningkatnya kecakapan siswa dalam menerapkan berbagai strategi. Disamping itu, dengan perlahan pula siswa akan lebih ahli dan lebih efisien lagi dalam menerapkan strategi dalam menyelesaikan soal fakta matematika, karena memiliki pengetahuan terkait fakta matematika yang sederhana akan memungkinkan siswa dapat mengatasai fakta matematika yang lebih sulit. Pada akhirnya, siswa dapat menyebutkan banyak kombinasi bilangan yang diperlukandengan mudah dan akurat ketika itu diperlukan.Misalnya ketika siswa diminta menghitung $8 \times 9$, siswa dapat menghitungnya dengan mengalikan 9 sebanyak tiga kali yaitu 18, 36, 72 dengan cepat dan mudah.

\section{Memberikan Masalah Riil untuk Dipecahkan}

Salah satu cara yang dapat dilakukan untuk memperluas pemahaman informal anak adalah memberikan masalah matematika sederhana dalam kehidupan sehari-hari dengan tanpa memberitahu bagaimana cara menyelesaikannya. Cara ini dilakukan mengingat pada saat anak masuk ke jenjang sekolah dasar, setidaknya sudah memiliki pemahaman sentral yakni bahwa suatu kuantitas tertentu dapat dipecah menjadi beberapa bagian yang jika diambil secara bersamaan semua bagian tersebut akan menjadi nol (original quantity), disamping itu siswa juga memahami bahwa jika mereka memiliki sesuatu sejumlah kuantitas tertentu kemudian mendapatkannya lagi, maka pada akhirnya kuantitasnya akan semakin banyak sebaliknya jika diambil atau hilang sebagian maka akhirnya kuantitasnya lebih sedikit (Resnik dkk, 1990). Adapun contoh masalah bisa diberikan misalnya, " Adik mempunyai permen karet sebanyak 6, kemudian kakak memberikannya lagi sebanyak 9. Berapa banyak permen karet yang dimiliki adik?” atau “ kakak berjanji akan memberi adik permen sebanyak 15 buah, saat ini kakak sudah mempunyai 6 permen. Berapa banyak lagi permen yang harus kakak beli agar dapat memberikan semuanya pada adik?"

Pada saat siswa mencoba menyelesaikan masalah tersebut, guru perlu memberi dorongan untuk menemukan solusi dengan menggunakan cara yang memungkinkan untuk dilakukan siswa, bisa dengan menggunakn objek hitung (jari, oral, atau manipulatif), melihat pola dll. Agar siswa dapat mengetahui cara yang paling efisien maka setelah siswa mengerjakan, guru dapat meminta siswa untuk berbagi satu sama lain dengan menceritakan cara yang digunakan.

Namun dikelas tertentu guru kadang mendeskripsikan beberapa metode berbeda yang sangat mungkin tidak dikenal siswa sehingga kemudian menjadi sulit tidak dipahami.Sebenarnya, guru bisa saja mengajukan strategi yang dibuatnya sendiri, namun perlu diperhatikan agar jangan membuat strategi tententu menjadi "diharuskan" sementara strategi yang lain diabaikan.Disamping itu guru juga tidak 
perlu kecewa jika siswa tidak langsung mengadopsi strategi yang dianggap lebih efisien, karena bisa saja pada saat itu, perkembangan siswa yang masih berada dibawah permukaan tersebut adalah yang paling pas untuk siswa yang bersangkutan.

\section{Aktivitas untuk Mengembangkan Strategi Penalaran Fakta Penjumlahan}

\section{a. Tambah Satu, Tambah Dua}

Buat dua jenis kartu dengan warna berbeda (misal Kartu Merah dan Kartu Putih) dengan jumlah tertentu (misal 10 kartu).Kartu merah berlabel +1, +2 sedangkan kartu putih berlabel 3,4,5,6,7,8 dst. Siswa secara bergantian mengambil kedua jenis kartu (masing-masing 1) secara acak, kemudian menyebutkan penjumlahan bilangan sesuai label angka yang ada pada kedua kartu, misalnya: “ 8 dua lebihnya adalah 10 ”.

\section{b. Penjumlahan dengan 0}

Sediakan beberapa kantong dengan warna (misal kantong kuning dan biru). Isi kantong kuning dengan objek hitung misal permen atau kelereng dengan jumlah tertentu 2,3,4,5 dst.Dan biarkan kantong biru kosong. Tanpa memberitahu bahwa kantong biru kosong, mintalah siswa untuk mengambil kedua kantong tersebut, dan menghitung banyak semua kelereng atau permen yang ada pada kedua kantong.Selanjutnya, siswa akan menyebutkan banyak isi kelereng atau permen pada kantong kuning misalnya 5, dan kosong pada kantong biru (0). Gurumengarahkan siswa menjastifikasi kalau sejumlah tertentu dijumlahkan dengan 0 maka hasilnya adalah bilangan itu sendiri.

\section{c. Menggunakan Bilangan 5 atau 10 sebagai Acuan}

Buat kartu berisi kolom-kolom berikut.
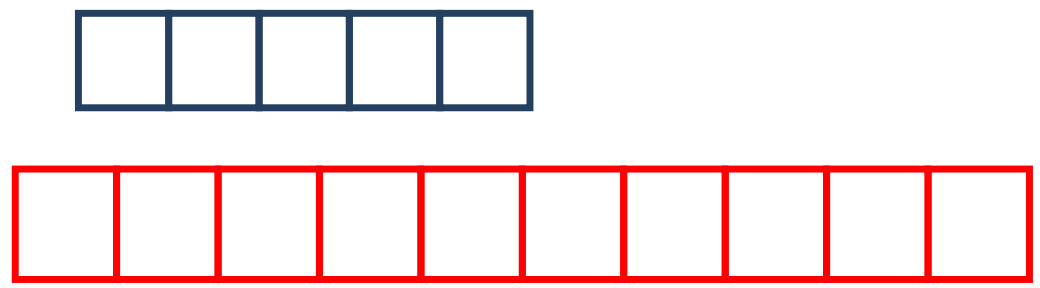

Sediakan juga sejumlah koin berwarna (merah dan biru) masing-masing 10 .


Mintalah siswa meletakkan sejumlah koin dengan warna berbeda untuk memenuhi kolom-kolom yang ada, kemudian menuliskan kombinasi bilangan yang merepresentasikan. 


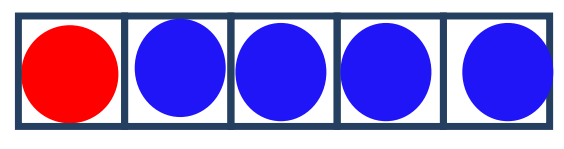

$1+4=5$



$3+2=5$
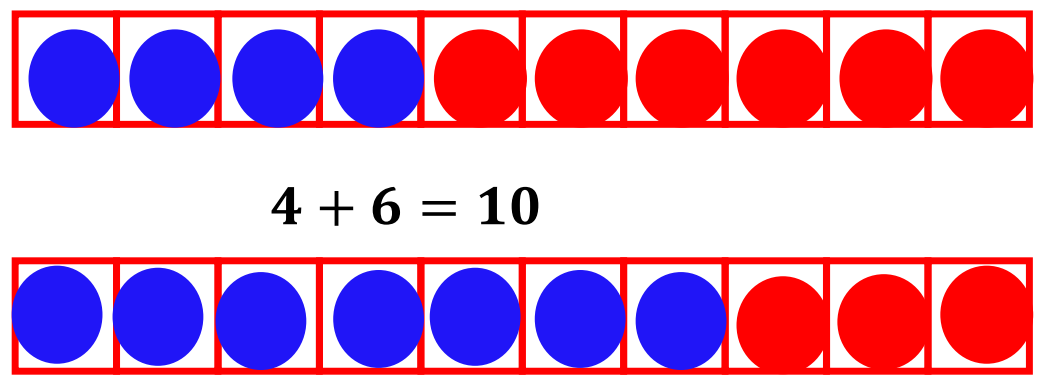

$$
7+3=10
$$

Selanjutnya daftar kombinasi bilangan yang membentuk 5 dan 10 dituliskan di papan tulis, untuk memastikan semua siswa dapat mengamati dengan baik.

\section{d. Kelipatan dua (double)}

Identik dengan aktifitas sebelumnya, guru dapat menyediakan kolom-kolom kosong yang harus diisi oleh siswa secara bergantian dengan melakukan penjumlahan dua bilangan yang sama mulai 0 sampai 10 .

\begin{tabular}{|l|l|l|l|l|l|l|l|l|l|l|l|}
\hline+ & 0 & 1 & 2 & 3 & 4 & 5 & 6 & 7 & 8 & 9 & 10 \\
\hline 0 & & & & & & & & & & & \\
\hline 1 & & & & & & & & & & & \\
\hline 2 & & & & & & & & & & & \\
\hline 3 & & & & & & & & & & & \\
\hline 4 & & & & & & & & & & & \\
\hline 5 & & & & & & & & & & & \\
\hline 6 & & & & & & & & & & & \\
\hline 7 & & & & & & & & & & & \\
\hline 8 & & & & & & & & & & & \\
\hline 9 & & & & & & & & & & & \\
\hline 10 & & & & & & & & & & & \\
\hline
\end{tabular}

Untuk mengisi klom berwarna kuning tersebut, mintalah siswa menggunakan objek hitung seperti aktivitas $\mathrm{c}$. 


\section{e. Dekat Kelipatan Dua}

Aktifitas ini merupakan kelanjutan dari aktifitas kelipatan dua.Dengan menggunakan tabel kelipatan dua, mintalah siswa mengisi kolom dekat kelipatan dua (warna merah) kemudian menuliskan daftar kombinasi dua bilangan yang hasil penjumlahannya dekat dengan kelipatan dua.

\begin{tabular}{|l|l|l|l|l|l|l|l|l|l|l|l|}
\hline+ & 0 & 1 & 2 & 3 & 4 & 5 & 6 & 7 & 8 & 9 & 10 \\
\hline 0 & & & & & & & & & & & \\
\hline 1 & & & & & & & & & & & \\
\hline 2 & & & & & & & & & & & \\
\hline 3 & & & & & & & & & & & \\
\hline 4 & & & & & & & & & & & \\
\hline 5 & & & & & & & & & & & \\
\hline 6 & & & & & & & & & & & \\
\hline 7 & & & & & & & & & & & \\
\hline 8 & & & & & & & & & & & \\
\hline 9 & & & & & & & & & & & \\
\hline 10 & & & & & & & & & & & \\
\hline
\end{tabular}

\begin{tabular}{|c|l|}
\hline $\begin{array}{c}\text { Kelipatan } \\
\text { Dua }\end{array}$ & \multicolumn{1}{|c|}{ Dekat Kelipatan Dua } \\
\hline 0 & $1=0+1,1=1+0$ \\
\hline 2 & $1=0+1,1=1+0,3=1+2,3=2+1$ \\
\hline 4 & $3=1+2,3=2+1,5=2+3,5=3+2$ \\
\hline 6 & $5=2+3,5=3+2,7=3+4,7=4+3$ \\
\hline 8 & $\ldots$ \\
\hline 10 & $\ldots$ \\
\hline 11 & $\ldots$ \\
\hline 12 & $\ldots$ \\
\hline$\ldots$ & $\ldots$ \\
\hline$\ldots$ & $\ldots$ \\
\hline 20 & $\ldots$ \\
\hline
\end{tabular}

\section{Aktivitas untuk Mengembangkan Strategi Penalaran Fakta Perkalian}

\section{a. Perkalian dengan $0,2,5,9$ dan 10}

Setelah belajar tentang fakta penjumlahan, siswa akan sudah familiar dengan kelipatan dua yang merupakan penjumlahan suatu bilangan sebanyak dua kali. Terkait perkalian dengan 0 , siswa perlu diberikan penjelasan bahwa jika $3 \times 0$ artinya adalah menjumlahkan 0 sebanyak tiga kali $(0+0+0)$, sedangkan $0 \times 3$ berarti , misal dalam setiap kantong hadiah berisi 3 permen, sedangkan anda sama sekali tidak mendapatkan hadiah, maka tentu anda tidak memiliki permen, dengan kata lain anda memiliki 0 permen. Hal ini juga berlaku untuk perkalian bilangan yang lain dengan 0 maupun sebaliknya. Pada perkalian dengan 5, guru dapat mengawalinya dari penjumlahan beruntun yaitu $0,5,(5+5),(5+5+5)$, dst hingga diperoleh $0,5,10,15$, 20, 25,...dst. Dari hasil tersebut dapat diperhatikan pola bilangan yang terbentuk.Selanjutnya, fakta-fakta perkalian yang diperoleh dapat ditulis pada kolom isian seperti berikut. Cara yang sama dapat dlakukan pada perkalian 10. Fakta terkait perkalian 9 juga cukup mudah dipelajari karena memiliki pola yang cukup jelas bisa diidentifikasi yakni: 1) Bilangan puluhan yang hasil perkalian selalu selisih satu 
dengan pengali dari 9 . Sebagai contoh $6 \times 9=54$ perhatikan bahwa 5 sebagai bilangan puluhan hasil hasil kali, satu kurangnya dari 6 . Contoh yang lain juga bisa diamati sendiri, 2) Jumlah digit bilangan hasil kali dua bilangan dengan 9 selalu berjumlah 9. Salah satu strategi yang bisa digunakan dalam menyelesaiakan perkalian 9 , bisa berangkat dari fakta perkalian 10 . Misalnya $8 \times 9$, cukup diingat bahwa $8 \times 10=80$, sehingga $8 \times 9$ adalah 8 kurangnya dari 80 yaitu 72 .

\begin{tabular}{|l|l|l|l|l|l|l|l|l|l|l|l|}
\hline $\mathrm{x}$ & 0 & 1 & 2 & 3 & 4 & 5 & 6 & 7 & 8 & 9 & 10 \\
\hline 0 & 0 & 0 & 0 & 0 & 0 & 0 & 0 & 0 & 0 & 0 & 0 \\
\hline 1 & 0 & 1 & 2 & 3 & 4 & 5 & 6 & 7 & 8 & 9 & 10 \\
\hline 2 & 0 & 2 & 4 & 6 & 8 & 10 & 12 & 14 & 16 & 18 & 20 \\
\hline 3 & 0 & 3 & 6 & & & 15 & & & & 27 & 30 \\
\hline 4 & 0 & 4 & 8 & & & 20 & & & & 36 & 40 \\
\hline 5 & 0 & 5 & 10 & 15 & 20 & 25 & 30 & 35 & 40 & 45 & 50 \\
\hline 6 & 0 & 6 & 12 & & & 30 & & & & 54 & 60 \\
\hline 7 & 0 & 7 & 14 & & & 35 & & & & 63 & 70 \\
\hline 8 & 0 & 8 & 16 & & & 40 & & & & 72 & 80 \\
\hline 9 & 0 & 9 & 18 & 27 & 36 & 45 & 54 & 63 & 72 & 81 & 90 \\
\hline 10 & 0 & 10 & 20 & 30 & 40 & 50 & 60 & 70 & 80 & 90 & 100 \\
\hline
\end{tabular}

\section{b. Memanfaatkan Fakta Perkalian yang Sudah Diketahui}

Jika diperhatikan kolom tabel perkalian di atas, masih ada sekitar 25 fakta perkalian yang belum terisi (warna putih).Jika siswa diminta untuk sekedar mengingat ke 25 fakta perkalian tersebut, tentu akan kesulitan. Untuk mengatasinya, cukup dengan menggunakan fakta-fakta perkalian yang sudah diketahui sebelumnya mulai dari perkalian dengan $0,1,2,5,9$, dan 10 .Contoh 1adalah $8 \times 4$, siswa dapat menggunakan fakta bahwa $8 \times 5=40$, artinya $8 \times 4$ adalah 8 kurangnya dari dari 40, yaitu 32 . Contoh 2 adalah7 $\times 6$ siswa dapat menggunakan fakta $7 \times 5=35$, artinya $7 \times 6$ adalah 7 lebihnya dari 35, yaitu 42 . Contoh 3 adalah $8 \times 7$, siswa dapat menggunakan fakta $8 \times 5=40$, artinya $8 \times 7$ adalah $2 \times 8=16$ lebihnya dari 40 , sehingga $8 \times 7$ adalah 56.

\section{c. Berlatih Menggunakan Fakta Perkalian}

Setelah fakta-fakta perkalian cukup dipahami, guru perlu melakukan upaya mendorong siswa menggunakan, bekerja dan mengksplorasi fakta matematika yang sudah diketahui, salah satunya dengan cara mendesain aktivitas-aktivitas yang bermakna sekaligsus menarik dan menyenangkan bagi siswa. Dengan terlibat dalam aktivitas matematika yang bermakna, siswa akan lebih baik lagi dalam memahami 
fakta matematika yang bahkan akan mengarah pada otomatisasi. Siswa akan lebih menikmati belajar matematika dan terhindar daridipaksa menghafal, cemas dan takut akan matematika.

Beberapa aktivitas yang bisa dilakukan diantaranya mengajukan soal fakta matematika yang lebih komplit, misalnya $12 \times 8$ dan mintalah siswa mengerjakan dengan menggunakan fakta matematika yang sudah dimiliki secara mental. Selanjutnya, guru akan mendapati banyak strategi yang dilakukan siswa, seperti beberapa contoh berikut:

\begin{tabular}{|c|c|c|c|}
\hline $10 \times 8=80$ & $12 \times 5=6 \times 10=60$ & $6 \times 8=48$ & $12 \times 2=24$ \\
$2 \times 8=16$ & $12 \times 3=6 \times 6=36$ & $2 \times 48=96$ & $24 \times 2=48$ \\
$80+16=96$ & $60+36=96$ & & $48 \times 2=96$ \\
\hline
\end{tabular}

Cara berikutnya bisa dengan menggunakan permainan, "Mendekat Sedekat-dekatnya dengan 100".Siswa berkelompok minimal dua orang, satu siswa bertugas mengetos dua dadu, siswa yang lain bertugas menggambarkannya pada kolom/grid $10 \times 10$. Ilustrasinya, misal dua dadu yang ditos muncul angka 3 dan 6, siswa kemudian mengarsir sebarang segi empat dengan panjang 3 persegi satuan dan lebar 6 persegi satuan. Hal ini dilakukan berulang hingga sedekat mungkin, memenuhi semua grid.

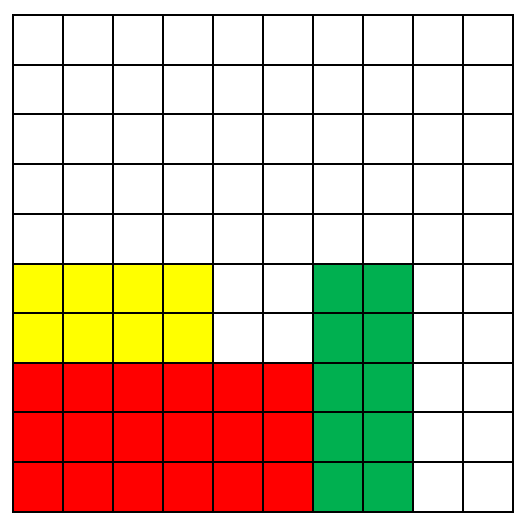

$\begin{array}{clr}3 \times 6=18 & \ldots \times \ldots=\ldots & \ldots \times \ldots=\ldots \\ 2 \times 5=10 & \ldots \times \ldots=\ldots & \ldots \times \ldots=\ldots \\ 4 \times 2=8 & \ldots \times \ldots=\ldots & \ldots \times \ldots=\ldots \\ \ldots \times \ldots=\ldots & \ldots \times \ldots=\ldots & \ldots \times \ldots=\ldots \\ \ldots \times \ldots=\cdots & \ldots \times \ldots=\ldots & \ldots \times \ldots=\ldots\end{array}$




\section{Hal-hal yang Harus Dihindari Dalam Membelajarkan Fakta Dasar Matematika}

Beberapa hal berikut perlu dihindari dalam prosesmembelajarkan fakta dasar matematika pada siswa karena akan menghambat proses penguasaan (mastery)dan kelancaran (fluency).

1. Membelajarkan fakta matematika secara berurut 0-9. Dalam membelajarkan fakta matematika guru lebih baik membiarkan siswa mengembangkan strateginya sendiri. Guru tidak perlu memaksakan strategi tertentu yang harus diikuti oleh seluruh siswa.

2. Membelajarkan fakta matematika dengan menghafal. Kemampuan mengingat fakta matematika sebenarnya secara otomatis akan efektif hanya jika siswa benar-benar siap dengan berbagai strategi penalaran yang dimiliki, kapan perlu digunakan dan bagaimana cara menggunakannya.

3. Melakukan Tes Berdurasi Waktu

Selain mempunyai keterbatasan sebagai instrument asesmen, beberapa dampak yang bisa muncul jika guru melakukan tes berdurasi waktu secara terus menerus untuk mengetahui kemampuan penguasaan fakta matematika siswa, diantaranya: 1) dapat menghalangi progress siswa dalam menguasai fakta matematika (Henry dkk, 2008) dan 2) dampak psikologi (Ramirez, 2013).

4. Menekankan pada siswa bahwa kemampuan penguasaan fakta matematika sebagai rintangan yang harus dilalui untuk melangkah ke tingkat lebih lanjut. Matematika saat ini merupakan mata pelajaran yang lebih menekankan pada penalaran dan pola serta kemampuan pemecahan masalah, bukan hanya sekedar masalah hitungan atau komputasi. Sehingga, siswa yang mungkin saja masih belum mencapai penguasaan fakta matematika, tidak boleh menghalangi siswa tersebut untuk memperoleh pengalaman matematika lebih lanjut.

\section{Kesimpulan}

Kelancaran atau penguasaan fakta dasar matematika bagian penting dalam pembelajaran matematika khusunya di level dasar (SD) karena akan sangat membantu siswa dalam menyelesaikan masalah matematika yang lebih komplit. Untuk mencapai kelancaran fakta matematika siswa perlu melalui beberapa fase, mencakup: 1) strategi menghtiung dengan menggunakan objek hitung, 2) strategi penalaran, dan 3) Menguasai (mastery). Dalam membelajarkan fakta dasar matematika guru perlu mengawalinya dengan menyajikan masalah riil dan membiarkan siswa mengembangkan strategi alaminya.

Hal ini dilakukan mengingat siswa ketika menginjak jenjang sekolah dasar setidaknya siswa sudah mempunyai pemahaman sentral terkait penjumlahan dan 
perkalian.Aktifitas untuk mengembangkan strategi penalaran fakta penjumlahan dapat dimulai dengan aktifitas "tambah satu tambah dua", penjumlahan dengan 0 , penggunaan 5 dan 10 sebagai acuan, kelipatan dua, dan dekat kelipatan dua. Untuk mengembangkan strategi penalaran fakta perkalian, dapat diawali dari aktivitas perkalian 0, 2, 5, 9 dan 10. Kemudian dilanjutkan dengan penggunaan fakta yang sudah diketahui untuk membangun strategi penyelesaian soal yang lebih sulit.Untuk mencapai kelancaran, pembelajaran fakta perkalian dapat diakhiri dengan aktivitas latihan-latihan misalnya berupa game yang menarik sehingga meningkatkan keterlibatan siswa dalam pembelajaran. Beberapa hal perlu dihindari agar tidak mengahambat siswa mencapai kelancaran fakta matematika diantaranya, memformalkan pembelajaran fakta matematika secara urut 0-9 dengan mengabaikan strategi penalaran yang dikembangkan sendiri oleh siswa, membelajarkan fakta matematika dengan menghafal, tes berdurasi waktu dan menjadikan penguasaan fakta matematika sebagai rintangan utama yang harus ditaklukkan sebelum melangkah pada level berikutnya.

\section{DAFTAR PUSTAKA}

Baroody, A. J. (2006). Why children have difficulties mastering the basic fact combinations and how to help them. TeachingChildren Mathematics, 13(1), halaman 22-31.

Boaler, J. (2015). What's Math Got To Do With It? How Teachers and Parents Can Transform Mathematics Learning and Inspire Success. New York: Penguin.

Frawley, C. (2012). Developing math fact fluency.didownload darihttp://www.ttacnews.vcu.edu/2012/02/developing-math-fact-fluency/. 21 Mei 2019 pukul 09.00 WIT

Greaney, K. (2015). Skills-based learning within a constructivist curriculum: The case for rote learning to automaticity the multiplication facts for maths and alphabetic skills for reading. Journal of Education, 14(2), halaman 1-8.

Henry, V. and R. Brown (2008). First-Grade Basic Facts: An Investigation Into Teaching and Learning of an Accelerated, High-Demand Memorization Standards. Journal for Research in Mathematics Education.39(2): halaman 153-183.

Henry, V. J., \& Brown, R. S. (2008).First-Grade Basic Facts: An Investigation into Teaching and Learning of an Accelerated, High-Demand Memorization Standard.Journal for Research in Mathematics Education, 39(2), halaman 156.

Krudwig, K. (2003). Get it right and get it fast! Building automaticity to strengthen mathematical proficiency.Focus on Learning Problems in Mathematics, 25(3).Didownload 
darihttps://www.thefreelibrary.com/Get+it+right+and+get+it+fast!+Building+ automaticity+to+strengthen...-a0152872836. 21 Mei 2019 pukul 09.00 WIT.

Nelson, P., Parker, D., \& Zaslofsky, A. (2016).The relative value of growth in math fact skills across late elementary and middle school.Assessment for Effective Intervention, 41(3), halaman 184-192.

Ramirez, Gerardo, Elizabeth A. Gunderson, Susan C. Levine, and Sian L. Beilock. 2013. Math Anxiety, Working Memory, and Math Achievement in Early Elementary School.Journal of Cognition and Development 14(2): halaman 187-202.

Resnick, Lauren B dkk. "From Protoquantities to Number Sense."Makalah dipresentasikan pada Psychology of Mathematics Educations Conference, Mexico City, 1990.

Woodward, J. (2006). Mathematics education in the United States: Past to present. Journal of Learning Disabilities, 37, halaman 16-31. 